\title{
The Significance of Positive Wassermann and Kahn Reactions in Leprosy
}

Ernest Muir and T. N. Roy.

Much has been written on this subject since 1923. It is generally acknowledged that both Wassermann and Kahn reactions may be strongly positive in cases which never during life show clinical signs indi

It is well known that in cases with positive serological findings during life no pathological signs may appear at autopsy. Murales-Otero examined two such groups, one leprous and the other non-leprous. In the former, 90 per cent. showed positive serological and negative pathological findings, as compared with 17.2 per cent. in the latter.

In an article describing the work of several collaborators (Hazen et al 1936) ${ }^{1}$ in the United States it is related that discrepancies in results were obtained when sera from the same supposedly non-syphilitic patients were sent to various serologists for examination. In a series of 50 leprous patients the positives varied in the hands of different serologists from 76 to 42 per cent.; in 36 malarial patients from 19.4 to 8 per cent.; in 53 tuberculosis patients from 7.7 to 0 per cent.; in 25 menstruating women from 12 to 0 per cent.; of 25 women not menstruating all gave negative results except that one of the thirteen serologists found 4 per cent. positive. Malaria and especially leprosy gave the largest numbers of positives and the greatest variations in results.

While in leprosy it is usual for a accompany a positive Wassermann, in some cases these two tests give contradictory results, the one becoming positive when the other is negative and vice versa.

Table I gives the results of repeated simultaneous Wassermann and Kahn tests, taken on the dates mentioned, in nine leprous patients under treatment in Calcutta. (The patients are indicated in the table and in the comments by their initials and the two tests by $\mathrm{W}$ and $\mathrm{K}$.)

The question naturally arises as to whether these cross purposes between two standard tests are to any extent caused by drug treatment. We therefore give three further cases in Table II. and detail the form of treatment given immediately before the dates of taking blood for examination. 


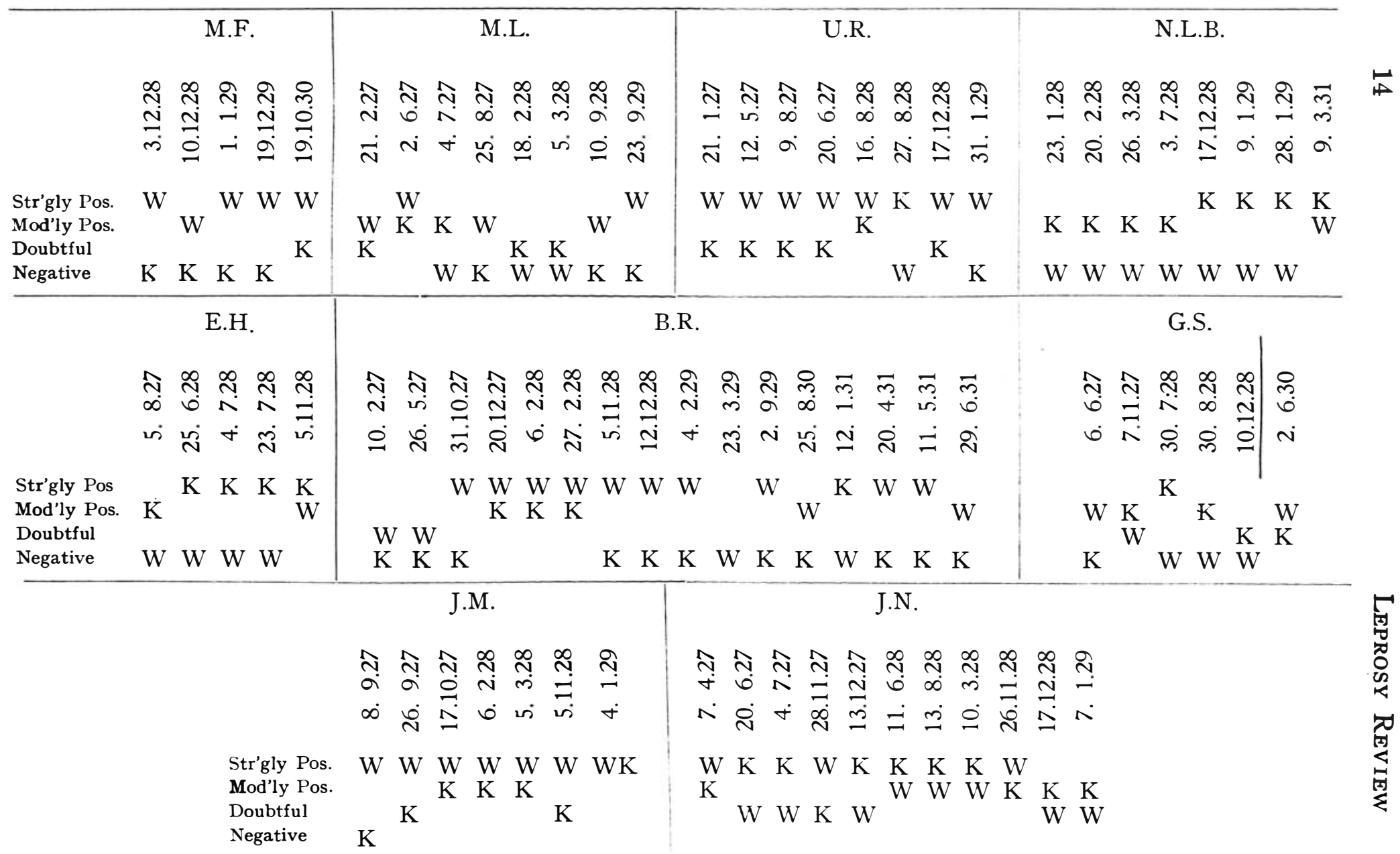


Notes on Table I.

M.F. Over a period of almost two years 5 double tests (W.R. and Kahn) showed a persistently positive Wasserman and a persistently negative Kahn.

M.L. To begin with the W.R. was moderately positive and the Kahı doubtful. On 2.6.27, while reacting to potas, iod. the Kahn became positive and remained positive a month later when the W.R. had become negative. After yet another month the position was again reversed. Later both became negative or doubtful, but seven months later, while the Kahn remained negative, the W.R. had again become positive.

U.R. After six months in which the W.R. was strongly positive and the Kahn doubtful, the position was reversed, and again after another six months the original position was restored.

N.L.B. Here we have the exactly opposite position to that in M.F., the Kahn being positive and the W.R. persistently negative, until after over three years it became moderately positive.

E.H. The record here is almost exactly the same as in N.L.B.

B.R. For two and a half years the W.R. is positive and the Kahn negative; on 23.3.29 the W.R. is negative, but strongly positive again six months later; then the Kahn takes advantage of a second lapse of the W.R. to negative, to become for once positive. After this the original position is restored.

G.S. Here we have another criss-cross similar to M.L., J.N. and B.R.

J.M. Here the Kahn, at first negative, later joins the W.R. in being positive, but becomes doubtful after two courses of bismuth; but two months later it is up at four plus.

J.N. Here for the first eight months the Kahn and W.R. appear to be at cross purposes, the one becoming positive as soon as the other became doubtful. Then for six months they are more or less in agreement, both being positive. Later, after a course of bismuth, finished on 26.11.28, the W.R. became strongly positive and then dropped to negative, leaving the Kahn still positive.

\section{Notes on Table II.}

S.6. During the period under re iew this patient was given seven courses of novarsenobillon or neosalvarsan, each consisting of six weekly injections. He also had 9 courses of avenyl (a mercury preparation soluble in oil) each consisting of 6 injections. He also was given massive doses of potassium iodide which however, produced little or no clinically noticeable constitutional disturbance. It is difficult to correlate in any way the administration of these drugs with the respective and relative changes in the W. R. and Kahn findings.

S.7. This patient beginning with a negative W.R. and doubtful Kahn was given a provocative dose of novarsenobillon, which was followed by the W.R. becoming positive and the Kahn negative, which they continued to be for a year in spite of treatment.

S.3. In this case the W.R. appears to follow tardily behind the Kahn, as is shown by taking the blood repeatedly at short intervals. It may be that in some cases changes which cause a positive or negative W.R. may be slower than those which cause corresponding changes in the Kahn. This might account for some but not for all of the differences. 
TABLE II.

Course of 6 injections of N.A.B. and

Bismuth cream ... ... ...

16 injections of .25 grams of avenyl

No injection of arsenic or mercury given but massive doses of K.I. given orally

After prov. N.A.B.

16 injections of avenyl

Course of K.I. (240 grains per dose)

ditto

10 Bismuth injections

240 grains K.I. orally and 6 injections N.A.B.

N.A.B. and avenyl course $\quad \ldots \quad \ldots$

$\begin{array}{cccc}\text { ditto } & \ldots & \ldots & \ldots \\ \text { ditto } & \ldots & \ldots & \ldots\end{array}$

$\begin{array}{lllll}\text { Treatment nil } & \ldots & \ldots & \ldots & \ldots\end{array}$

240 grains K.I. orally $\quad \ldots \quad \ldots$

$\begin{array}{lllll}\text { Treatment nil } \ldots & \ldots & \ldots & \ldots\end{array}$

Neosal and avenyl $\quad \ldots \quad \ldots \quad \ldots$

N.A.B. and avenyl and bismuth $\ldots$

$\begin{array}{llll}\text { N.A.B. and avenyl } & \ldots & \ldots & \ldots\end{array}$

$\begin{array}{lllll}\text { Avenyl } & \ldots & \ldots & \ldots & \ldots\end{array}$

$\begin{array}{llllll}\text { K.I. } & \cdots & \ldots & \ldots & \ldots & \cdots \\ & \cdots & \cdots & & \cdots & \end{array}$

$\begin{array}{llllll}\text { ditto } & \ldots & \ldots & \ldots & \ldots & \ldots \\ & \ldots & \ldots & \ldots & \ldots\end{array}$

$\begin{array}{lllll}\text { Treatment nil } \ldots & \ldots & \ldots & \ldots\end{array}$

$$
\begin{array}{ccccc}
\text { ditto } & . . & \ldots & \ldots & \ldots \\
\text { ditto } & \ldots & \ldots & \ldots & \ldots \\
\text { ditto } & \ldots & \ldots & \ldots & \ldots \\
\text { ditto } & \ldots & \ldots & \ldots & \ldots \\
\text { ditto } & \ldots & \ldots & \ldots & \ldots \\
\text { ditto } & \ldots & \ldots & \ldots & \ldots \\
& & & & \\
& & & & \\
& & &
\end{array}
$$

Provocative dose of N.A.B. $0.45 \mathrm{~g}$. ...

$\begin{array}{lllll}\text { Treatment nil } \ldots & \ldots & \ldots & \ldots & \end{array}$

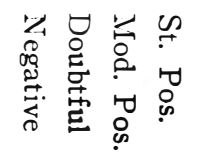

$$
\begin{aligned}
& \text { \& 23.7.26 }
\end{aligned}
$$

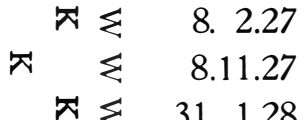

$$
\begin{aligned}
& \text { 26. } 6.28 \\
& \text { 10. } 7.28 \\
& \text { ¿ 25.9.28 } \\
& \text { 30.10.28 } \\
& \text { 26. } 3.29 \\
& \text { 刃 2. } 7.29 \\
& \text { 25. } 2.30 \\
& \text { त 22. } 7.30 \\
& \text { 26. } 8.30 \\
& \text { \23. } 9.30 \\
& \text { } 14.10 .30
\end{aligned}
$$

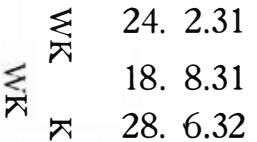

$$
\begin{aligned}
& \sum \pi \quad \text { त } 18.10 .32 \\
& \text { 岤 } 8 \quad 1.11 .32 \\
& \text { \& } 8.11 .32 \\
& \text { \& } \quad \text { त } 15.11 .32 \\
& \text { \& } 22.11 .32 \\
& \text { \& } 29.11 .32 \\
& \pi \xi \\
& \& \quad 13.12 .32 \\
& \S \quad 20.12 .32
\end{aligned}
$$

Provocative dose of N.A.B. $0.45 \mathrm{~g}$. ...

16 injections of N.A.B. (form 0.18

$$
\text { to } 0.54 \mathrm{~g} \text {.) } \ldots \quad \ldots \quad \ldots \quad \ldots
$$

Treatment nil ... $\quad \ldots \quad \ldots \quad \ldots \quad$ त ditto 
S.3.

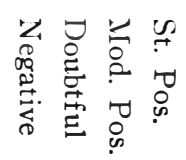

2 Courses of N.A.B. and avenyl $\ldots$

Provocative dose of N.A.B. $0.45 \mathrm{~g}$.

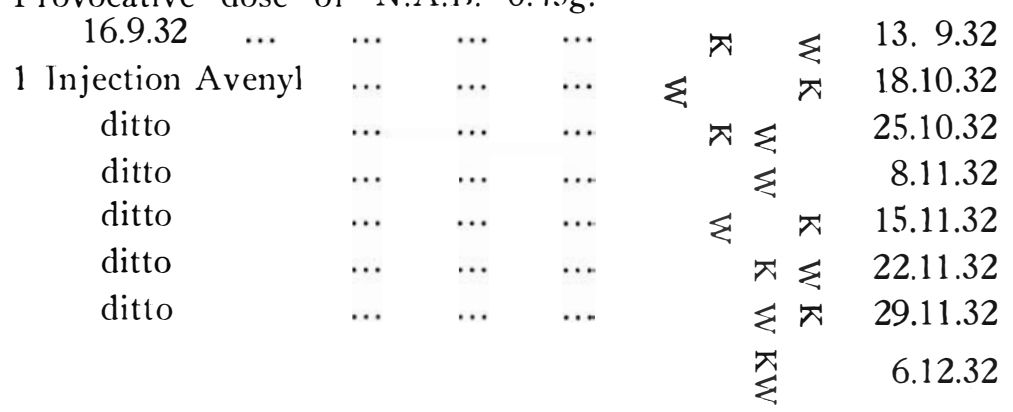

The Wassermann tests were conducted by the Serological Department at the School of Tropical Medicine, Calcutta. The Kahn tests were carried out in the leprosy department by an experienced chemist, the results being read by one of us (E.M.). Great care was taken to avoid any errors of technique, to which the differences between the results of the two tests cannot be attributed.

\section{Discussion.}

In early and slight cases of leprosy, in which there is no profound constitutional disturbance, and in which the patient is in reasonably good general health, a persistently strong or moderate Wassermann or Kahn reaction should be taken as indicating spirochetal disease; but in advanced cutaneous or mixed cases, especially in those who are sensitized and subject to attacks of " lepra reaction," a positive serological result alone, in the absence of positive history or clinical signs, should not justify a diagnosis of accompanying syphilis. In such cases serological tests (both Kahn and W.R.) should be repeated frequently so as to ascertain whether they are consistently positive.

Ishibashi $(1937)^{2}$ examining 138 lepers, found 22.5 per cent. Wassermann-positive. $\mathrm{He}$ considers that this frequency is due to a special antibody in the serum of lepers. Experimenting with animals he found that the serum of rabbits, immunised with ether-soluble substances obtained from acid-fast bacilli (avian tubercle bacilli) was often Wassermann-positive.

A positive serological reaction (Wassermann or Kahn) 
is in some cases undoubtedly due to accompanying syphilis. But the great variations in total results as reported by Hazen and others, the great variations from time to time in individual cases, and marked lack of coincidence of Wassermann and Kahn results in these cases, suggest that a fair proportion of positive serological results in leprosy is due not to accompanying syphilis but to some other factor.

Ishibashi's work seems to throw some light on this other factor, which may be connected with the breaking up of acidfast bacilli inside the body and the setting free in the serum of certain fractions. This would seem to be the more likely, for "lepra reaction," during which there is more active breaking down of leproma, and connected with which bacillaemia is more commonly found, appears according to many writers to produce a higher proportion of serological positives.

References: 1. Hazen et a1., Int. J1. of Leprosy, Vol. IV. No. 3, 1936, p. 315.

2. Ishibashi, Tohoku J1. of Experimental Medicine, Jan.1937, p. $287 / 315$. 